\title{
The case against alternative currencies
}

Politics, Philosophy \& Economics 2022, Vol. 21 (I) 75-93 (C) The Author(s) 2021

Article reuse guidelines: sagepub.com/journals-permissions DOI: $10.1177 / 1470594 \times 2$ II 1065784

journals.sagepub.com/home/ppe

\author{
Louis Larue \\ Post-doctoral fellow, Department of Philosophy, \\ Linguistics and Theory of Science, University of \\ Gothenburg, Sweden
}

\begin{abstract}
Local Currencies, Local Exchange Trading Systems, and Time Banks are all part of a new social movement that aims to restrict money's purchasing power within a certain geographic area, or within a certain community. According to their proponents, these restrictions may contribute to building sustainable local economies, supporting local businesses and creating "warmer" social relations. This article inquires whether the overall enthusiasm that surrounds alternative currencies is justified. It argues that the potential benefits of these currencies are not sufficient to justify the restrictions they impose on money's purchasing power. Turning these currencies into effective channels of change, by increasing their scope and their strength, could severely hinder the pursuit of social justice, in a way that is probably not even necessary for achieving their objectives. The paper concludes that large-scale limitations of money's purchasing power are, therefore, undesirable.
\end{abstract}

\section{Keywords}

alternative currencies, complementary currencies, financial ethics, social justice, environmental ethics

\section{Introduction}

A large variety of new alternative currencies has appeared in recent decades, as a way to challenge or to complement the official, dominant currencies. Local currencies, Local

\footnotetext{
Corresponding author:

Louis Larue, Post-doctoral fellow, Department of Philosophy, Linguistics and Theory of Science, University of Gothenburg, Sweden.

Email: Louis.larue.2@gu.se
} 
exchange trading systems, Carbon currencies, Times banks and Regional currencies, are all examples of this new trend. Despite their apparent variety, what they all have in common, and what sets them apart from official currencies such as euros or dollars, is that their possible uses are limited in some way: they are valid only within some geographic area, or within some community, or for specific goods and services. ${ }^{1}$ These currencies have benefited from enthusiastic support from academics (Blanc, 2018; Fare and Ould Ahmed, 2017) and political activists alike (Derudder, 2014). According to their proponents, the restrictions they impose on money's purchasing power allows them to bring about important benefits. They argue that they may help to build sustainable local economies (Lietaer et al., 2012), support local businesses (Gregory, 2009) or create "good" or "warmer" social relations (Servet et al., 1999).

The purpose of this paper is to inquire whether the overall enthusiasm that surrounds alternative currencies is justified. It aims to fulfil a gap in the literature, which has mainly focused on evaluating their empirical impacts on society and the environment (e.g. Marshall and O'Neill, 2018; Michel and Hudon, 2015) and on analyzing the moral motivations of citizens supporting such initiatives (Blanc and Fare, 2016; Meyer and Hudon, 2017, 2018). Few authors, however, have studied the normative implications of these currencies (for an attempt, see Mildenberger, 2019; Larue et al., 2022). This article aims to show that these currencies give rise to important normative problems that deserve careful examination. At first sight, this may not be obvious: currently, the use of these currencies is purely voluntary and not very widespread. Why would they be an issue for justice?

My reply to this question starts in section 2, where I introduce the main specific traits of alternative currencies. I then delineate the case in their favour. I show that what ultimately may justify the existence and growth of alternative currencies is their potential economic, social and environmental benefits, that is, the benefits that would arise if they reached wider adoption and larger circulation. The importance of the word "potential" is not always grasped by proponents of alternative currencies. On the one hand, as we shall see in section 2, enthusiastic support for these currencies abound in the theoretical literature. On the other hand, the empirical part of the literature, overall, holds that these currencies have not been able to deliver on their promises (Marshall and O'Neill, 2018; Michel and Hudon, 2015). In this paper, I attempt to make sense of these somewhat contradictory claims by arguing that their benefits are primarily potential, that is, that they have a chance to materialize only if alternative currencies achieve wider adoption. In other words, the defence of alternative currencies presupposes that they can and should circulate much more widely within society, as some authors have consistently argued (e.g. Lietaer et al., 2012; Michel and Hudon, 2015).

Widespread use of alternative currencies will perhaps increase their chance of achieving their objectives, but it will also give rise to several issues of justice. The three central sections of this paper argue that the potential benefits of these currencies are not sufficient to justify the restrictions they impose on money's purchasing power, and that these benefits need to be balanced against their potential consequences for social justice. First, the greater the weight of these currencies in the economy, the more they will reduce people's real opportunities (section 3). Second, their growth would also unjustly affect how the burdens of reducing environmental harms are distributed among consumers (section 4). Third, it would hinder the possibility to redistribute incomes and wealth in a just 
and efficient way (section 5). I show that the restrictions that these currencies would impose are disproportionate to their aims, even if these aims may be valuable. Their detrimental consequences on justice can hardly be justified by the pursuit of other valuable goals, such as environmental sustainability or social cohesion, for there exist other reforms, such as environmental taxation, that might achieve similar objectives without curtailing the pursuit of social justice.

The main conclusion of this article is that there is a dilemma between what these currencies can achieve and how they may affect justice. Currently, small-scale experiments are not achieving any significant outcome. As they hardly have any impact on social justice either, there is no reason for the state to forbid their development. However, turning these currencies into effective channels of change, by increasing their scope and their strength, would severely hurt justice, in a way that is probably not even necessary for achieving their objectives. Large-scale limitations of money's purchasing power are, therefore, undesirable.

\section{The Case in favour of alternative currencies}

What is the appeal of alternative currencies? What do they promise to achieve? Let me illustrate the case in their favour with a simple stylized example. Take a small village, somewhere in Europe, that has been somehow left behind economically and socially: the young have moved to the cities, and local shops are struggling to compete with supermarkets, so that money flows away and fails to sustain the local economy. Moreover, environmental issues add up to these economic and social problems. Most consumer goods come from outside of the village, which generates pollution, waste and other environmental problems.

This is where Local currencies, Local Exchange Trading systems (LETS), and other alternative currencies, come in. Their proponents claim that, because they restrict exchanges locally, or within a community, these currencies can best serve certain social, environmental or economic purposes, even at a relatively small scale. In the following paragraphs, I first explain their principal characteristics, then show what these restrictions entail, and finally review some of their key potential benefits.

What distinguishes these currencies from official currencies such as euros or dollars is that their uses are limited according to some criteria: they are valid only within some geographic area (Local currencies), or within some community (LETS, Time Banks), or for buying specific goods and services (For a detailed presentation, see Blanc, 2018; Lietaer et al., 2012). Let me present two of the most widespread forms of alternative currencies. Local currencies are valid only locally, to buy goods produced (or, at least, processed) locally. People can have access to Local currencies either by selling some products, or by exchanging euros or dollars against them. Each local currency relies on an organization, usually not-for-profit and run by volunteers, that keeps track of all transactions and stores on a bank account an amount of euros (or dollars) equivalent to the amount of Local currencies in circulation. So no money creation takes place here. LETS, on the other hand, are a complex form of barter between members of a local community. In LETS, the account of each member is credited each time this member provides a service and debited each time she receives a service from another member (Servet 
et al., 1999). Thus, money creation takes place through the exchange of services, and money takes the form of debt certificates, valid only within a certain community of members. Finally, note that current regulations are rather permissive with regard to the creation and use of alternative currencies: no formal barriers presently exist to prevent their spread (Attout et al., 2013). On the contrary, public authorities have often encouraged the development of such initiatives (Blanc and Fare, 2013). In contrast, banks and other financial institutions have had almost no role to play in these schemes. Actually, there is no market for alternative currencies. As of now, it thus remains impossible to exchange them for one another.

The key mechanism that drives their impact on the environment and society is that they restrict the purchasing power of money locally, or within a community. What do these restrictions entail? First, alternative currencies will effectively localize the economy if, and only if, they are not convertible into euros or other universal currencies. For their impact on the local economy would disappear if they could buy any good produced worldwide. While the possibility to convert one's money might reassure potential users, it also undermines the capacity of these currencies to effectively impact the economy or the environment, as people can escape local restrictions by buying back dollars or euros. This point is often overlooked. Arnsperger (2011: 10) and Douthwaite (2012: 191-192), for instance, take for granted that alternative currencies should remain convertible into euros or dollars. However, this would contradict their purpose of restricting the use of money locally, or within a community. Second, these currencies should be sufficiently widespread: if they make up for only a tiny part of people's income and wealth, they will be unlikely to effectively impose any restriction on their behaviour.

What is the justification for such restrictions? How could they be of any help for the villagers left behind in the example above? First, when exchanges take place within a local area and involve the members of a relatively small community, they may exhibit certain qualities, related to the personal sphere, that differ starkly from the impersonal character of global exchanges. For instance, LETS are usually put forward as means of social integration, which foster informal exchanges and mutual assistance, thanks to the fact that they circulate only within a given community of users (Servet et al., 1999). Because they concern only a small group of committed participants, they may allow people at the margin of society, who do not take part in common social and economic activities, to engage in local exchanges, to meet people there and, consequently, to build a new social network (Oliver Sanz, 2016). Second, through their ability to restrict exchanges to the local level, these currencies may also exhibit some economic benefits for local and regional economies, by helping local producers and fostering local exchanges (Gregory, 2009; Williams, 1996). Finally, some authors also think they may play an important role in a sustainable economy: by putting limits to global exchanges, they may allow to reduce pollution and transportation costs, and raise awareness about environmental issues (Brooks, 2015; Seyfang and Longhurst, 2013).

Their appeal is thus threefold. First, they appear to tackle genuine social, economic and environmental issues. Second, they do not require the involvement of the State, or other "big" institutional actors. They are bottom-up small-scale experiments, driven by groups of citizens at the local level. Third, they provide a simple and (at first sight) harmless solution to these problems: make sure money circulates locally, or within a small 
community of users. That latter claim is of great importance. The benefits of alternative currencies depend on their ability to restrict the purchasing power of money locally. As already argued, if local currencies could buy any good produced worldwide, their impact on the local economy would disappear.

In this article, I shall not challenge the fact that many local communities around the world are facing serious economic, social or environmental threats, such as the loss of local jobs, the closure of local shops, and the related environmental harms of globalization. The capacity of small-scale alternative currencies to tackle these issues is more questionable, though. Recent empirical findings have cast doubts on their alleged benefits. These currencies have not had any significant impact on the economy or the environment (Blanc, 2018: 96-101; Dittmer, 2013; Marshall and O’Neill, 2018; Michel and Hudon, 2015). Some authors did find some positive correlation between the use of such currencies and social cohesion, though (Fare and Ould Ahmed, 2017; Graugaard, 2012; Nakazato and Hiramoto, 2012; Ould Ahmed, 2015). Michel and Hudon (2015: 168) summarize these findings by writing that they contribute to "building communities of trust, support and stronger relationships [while] fostering social inclusion of excluded groups". Similarly, Fare and Ould Ahmed (2017: 18) conclude their overview of the literature by claiming that these currencies have the potential to promote the "social uses of money", even if that potential might not be fully realized. However, several authors have also raised doubts on their real social impact. Already at the advent of Local currencies, more than 20 years ago, Peacock (2000: 55) noted that "the empirical evidence shows a strong bias towards those people in gainful employment and those who are well-educated and well-off', a conclusion which is shared by Aldridge and Patterson (2002) and Bowring (1998). More recently, Blanc (2018: 71-72) has come to a similar conclusion and acknowledged that these currencies have rarely delivered on their promises to strengthen social cohesion.

One possible explanation for this lack of impact is the fact that their circulation remains extremely limited in comparison to official currencies (Fare and Ould Ahmed, 2017). We could conjecture that alternative currencies would deliver on their promises if only their size reached a sufficient threshold. In other words, all the benefits listed above are mainly potential benefits. The potential nature of the benefits of alternative currencies explains why so many authors have argued that their weight in the economy should grow (Lietaer et al., 2012; Michel and Hudon, 2015). They contend that even a slight increase in the use of these currencies might bring about important benefits, especially for the environment, as they would then be able to localize the economy and reduce pollution induced by global trade.

This article wishes to take these proposals seriously. What if it were true that their benefits were real? What if alternative currencies could in fact deliver on their promises? At first sight, assuming that they would be successful if wider adoption was achieved may seem controversial. How alternative currencies would work on a large scale is simply unknown (Larue, 2020b). Moreover, for now, these currencies have largely failed to deliver on their promises. How plausible is the assumption that they would suddenly be able to achieve their goals if only they could grow?

This assumption does not aim at empirical plausibility. Its main purpose is to take proponents of alternative currencies at their word. The case in their favor almost entirely 
relies on speculations on their potential benefits. As I have just argued, many of their proponents believe that they could deliver on their promises if only they could grow. This article aims to play by the same game and show that, even if we are extremely charitable towards alternative currencies, we have very good reasons to object to their growth. A second justification for this assumption is that it allows to set aside endless empirical controversies. Empirical speculations are probably unavoidable when discussing monetary reforms. As for other radical reforms such as basic income or sovereign money, introducing alternative currencies on a large scale would entail many institutional, social, and economic transformations that are hard to foresee. Moreover, the empirical literature is presently unable to provide any indication concerning their potential success or failure if they grew bigger. So I shall be charitable and assume that they will be able to have a significant impact. I will also be honest and consider all the other possible consequences of that growth, including its potential effects on social justice.

In short, studying an ideal scenario where they are successful and more widespread will allow to determine whether supporting these currencies does in fact make sense. It will also illustrate that the importance of the empirical controversy on their impact might be exaggerated: if it turns out that they are empirically unsuccessful, we have empirical reasons to doubt their relevance; alternatively, if it turns out that they would be successful if their reached wider adoption, the following sections will show that, even under very ideal empirical assumptions, we nevertheless have normative reasons to oppose the growth of alternative currencies. For if one takes the case in their favour seriously, one must also take into account how increasing their weight in the economy could threaten social justice.

Before turning to the heart of the argument, note that assuming that their weight in the economy increases will have several important methodological consequences for our analysis, which need to be spelled out very clearly. First, it would mean that the use of alternative currencies would no longer be voluntary. If one takes seriously the claim that they should grow, one must acknowledge that this requires active support from the state. For, when their use is voluntary, they usually fail to achieve widespread adoption (Blanc, 2018). Moreover, their growth would also entail that they would affect the well-being of many who might not have wished to use them, as increased use will lead to increased restrictions on money's purchasing power. For these two reasons, it is justified to inquire whether increasing their weight in the economy will raise concerns for justice. Even if imposing tighter limits on the purchasing power of money might actually achieve certain social or environmental objectives, we must balance it against its potential threats to social justice. I will show that there are several tensions between the possible environmental and social achievements of this proposal and its harmful consequences on justice. As we shall see, the strength of these tensions is partly an empirical matter (are these achievements real and effective?), partly an issue of values (do environmental or social benefits outweigh the harms done to justice?).

\section{Effects on opportunities}

The first tension concerns the effect of alternative currencies on opportunities. As the weight of these currencies grow, they will increasingly restrict the purchasing power 
of money locally, or within a community of users. Limiting the purchasing power of money to a specific area or community will inevitably restrict what a person's income and wealth can buy, that is, his or her opportunities. Clearly, when you receive a $100 €$ bill, your possibilities are much larger than when you receive a voucher only valid locally or within a specific community. Therefore, the greater the weight of such currencies in the economy, the more they will restrain people's opportunities. Is that justified?

Currently, as has already been stressed, the use of these currencies is purely voluntary. People may thus agree to receive part of their salary in local currencies, or to exchange goods and services for those currencies. Clearly, no injustice arises if these are voluntary exchanges. Problems of justice may arise if generalizing the use of these currencies becomes public policy, that is, if a state, a regional entity or a municipality enforces its use and promotes its growth. Suppose a government is convinced by the claim of proponents of alternative currencies that achieving certain environmental, social or economic objective requires expanding their use, for instance through (partial) payment of salaries and benefits in ACs. In that case, acceptance would no longer be voluntary, and opportunities would be reduced without consent.

This clearly seems unjust. Opportunities greatly matter to us, because we usually care about the freedom to do what we might want to do with the resources we have at our disposal. I take that intuition to be one core element of egalitarian theories of justice. Despite their many disagreements, most egalitarians stress that one of the main purposes of justice is to endow all individuals with the real opportunity to pursue one's own reasonable life plan. Dworkin (1985: 192) claims that resources should be "devoted to satisfying the ambitions" of each individual . Sen (1992: 36) emphasizes the importance of providing people with the adequate "means to freedom", which echoes Rawls' claim that political liberalism should guarantee "sufficient all-purpose means for citizens to make intelligent and effective use of their freedoms" (Rawls, 2005: xxxix). In a similar vein, Van Parijs (1995: 25) claims that a just society is one in which "each person has the greatest possible opportunity to do whatever she might want to do."

The proponents of alternative currencies could reply that the entire point of their proposal is to restrict people's opportunities, so as to achieve certain environmental, economic, or social benefits. Let's assume, for now, that these are valuable objectives. We thus face a trade-off: If the circulation and use of alternative currencies increase, we can assume that they will have some positive effects (on the environment, for instance) but also detrimental consequences for social justice. This creates an acute problem for alternative currencies, for one cannot have the benefits without paying the costs. The only way to weaken the effects on justice would be to put limits on their circulation. Some, for instance, may argue that people could be allowed to keep a significant amount of their salary in euros, or that local currencies could be convertible into euros. As was demonstrated in the previous section however, that move would reduce their capacity to impact society in a significant way. If one wants to retain a significant role for alternative currencies, that trade-off is unescapable.

One way to "solve" that dilemma would be to play down the value of their objectives and to get rid of these currencies entirely. I would like to take these goals seriously though, and inquire whether reaching them really requires generalizing the use of these currencies. A theory of justice that calls for the fair distribution of real opportunities 
among all citizens would certainly advocate some regulations to avoid environmental harms, for instance. Actually, Rawls often insists on the "intelligent" use of freedom and Sen attaches great importance to people's opportunities to do "what they have reasons to value". ${ }^{2}$ That is, life plans should be in some sense reasonable, which means that people should have reasons to embrace them, that they should be capable of reflecting upon their conception of the good life. It also means that these plans may be revised if it happens that they harm others in an unjustified way or if they do not comply with the demands of a just society. The latter point entails that justice does allow for some limitations of people's opportunities in some specific cases. The existence of environmental harm, for instance, provides a very good reason to limit the capacity of some people to pollute in order to protect the well-being of others (including future generations). However, alleviating such harms need not require the abandonment of the universality of money, especially if there exist other policy options, such as environmental taxation, that can achieve the same aim with fewer restrictions.

The general point I want to make is the following. The goals of alternative currencies are certainly legitimate. Local communities across Europe and elsewhere, especially in rural areas, do suffer from serious economic, social and environmental problems. However, increasing the weight of alternative currencies is a disproportionate response to these problems. Even if it might bring about some benefits, it would restrict people's opportunities in a way that is both harmful for justice and not necessary to achieve those benefits. In the following paragraphs, I shall argue that, for each of their objectives, there exists a policy that is both as efficient and less harmful for justice than generalizing the use of alternative currencies. I shall study in detail the case of their environmental objectives, because they are not controversial and have attracted much hope and enthusiasm (e.g. Lietaer et al., 2012). In fact, the promise to tackle environmental harm seems a very strong reason to support these currencies, and one should thus consider it thoroughly. My analysis shall be more succinct on their economic and social objectives, for the argument will in essence be the same. Moreover, these may be more controversial objectives, which may not gather universal agreement.

A good candidate to tackle environmental harm is environmental taxation, understood as a per unit tax on polluting goods. Ideally, the optimal environmental tax rate for a given product should equal the marginal environmental damage generated by that product, so that its price takes into account the negative externality of consuming or producing that product. Even if determining the exact tax rate might be difficult, several studies have shown that environmental taxation was among the most efficient ways to fight pollution and global warming (Fullerton et al., 2008; Hammar et al., 2004; Sterner, 2007). On the contrary, so far, existing experiments of alternative currencies have not impacted the economy in a significant way (Michel and Hudon, 2015). However, we lack empirical evidence on the efficiency of increasing the weight of these currencies in the economy, for nothing close to a large-scale experiment has ever seen the light. One of the largest experiments, the WIR in Switzerland, is still extremely small compared to the Swiss economy (Stodder, 2009).

One possible conclusion of that empirical comparison would be that these currencies do not stand a chance to influence the economy, the environment or social cohesion in any meaningful way. Imposing an environmental tax seems more likely to reduce the 
environmental impact of economic activities than encouraging the use of currencies that strictly restrict money's purchasing power. This conclusion may be too hasty, though, for alternative currencies have not had the chance to prove their worth on a large scale. For the sake of the argument then, and to give full credit to proponents of alternative currencies, I will take a slightly unrealistic step. Recall that the aim of this article is to see what would happen if these currencies would become more widespread. In particular, I want to know whether increasing their scope and size, as some of their proponents advocate, would not come at a cost for social justice. Therefore, I shall make the assumption that taxation and the generalization of alternative currencies can both tackle environmental degradations with the same effectiveness. That assumption puts into parentheses the empirical differences between the two policies and makes possible to focus on their normative underpinnings. Its purpose is to show that we do not simply have empirical reasons to doubt the effectiveness of alternative currencies, but also normative ones. Given this assumption, which option should one favour?

Even if we assume they have the same effectiveness, I shall argue that we should favour environmental taxation, because it restricts people's opportunities much less than a policy that would increase the weight of alternative currencies. To do so, let me specify what I mean by opportunities. In this paper, opportunities are said to be formal if they merely amount to the absence of legal constraints. Opportunities are real if they entail both the formal freedom and the concrete possibility to perform some action or to have access to some good. Both conditions are necessary and sufficient to define a real opportunity. ${ }^{3}$ One may have the concrete possibility, that is, the adequate means, to perform an act without having the formal freedom to perform it (e.g. theft). One may also have the formal freedom without the concrete possibility (e.g. buy a house).

Comparing the impact of different policies on people's concrete possibilities is a difficult task. For different environmental policies affect different people's concrete possibilities very differently (their income, their wealth, or their knowledge, for instance). Environmental taxation, for instance, can impact people's incomes and wealth differently depending on whether one lives in the countryside or in town, and whether one works full-time or part-time. Moreover, people may be (at least partly) held responsible for their choices, so that the effect of environmental policy on their plans of life may not be necessarily unjust, if one can show that they actually chose to live in a certain way or a certain place. I shall leave these distributive worries aside for now, and shall return to them in the next two sections. I do not deny their importance but want to consider another normative aspect of these environmental policies first.

Contrary to concrete possibilities, the way a given policy affects different individuals' formal opportunities does not vary across persons (or not much). The law applies to everyone equally. So one can compare how different policies affect people's formal opportunities. I contend that, among policies that have the same impact on the environment, we should choose the one that least restricts people's formal opportunities. This claim is, I think, uncontroversial and in line with very basic and widely shared intuitions in favour of liberty.

Taxation does restrict people formal freedom but less than alternative currencies (if widespread). In some cases, the social or environmental cost of producing, transporting or consuming a given product may be so high that it may require punishing rates of 
taxation or the complete ban of the product. In general, however, taxation maintains the formal freedom to do whatever one wants to do (including the consumption of polluting goods) while making the concrete possibility to consume or produce a function of its cost for others (if it is adequately designed). On the contrary, increasing the weight of alternative currencies would severely restrict the formal freedom of consuming goods produced outside the local or the community level. Therefore, if a choice needs to be made among these two alternatives (environmental taxation or alternative currencies), and if one assumes equal effectiveness of both alternatives, environmental taxation should clearly be preferred. In sum, one need not renounce money's universality in order to achieve sustainability: giving a greater place to alternative currencies would be both unjustly and unnecessarily restrictive. They may still have a place within the monetary system, but one small enough so as not to constitute a problem for social justice. Generalizing the use of alternative currencies is thus only a second-best option: if, for some reason (political or otherwise), taxation is not feasible, then the latter strategy may be acceptable. I am agnostic concerning which of these two policy proposals is the most politically feasible. My guess is that taxation is more likely to be implemented at some point, for it does not require a profound systemic change, contrary to the introduction on a large scale of alternative currencies.

What about other objectives? As we have seen, alternative currencies are often praised for bringing back social life where it had faded away (e.g. Servet et al., 1999). Similarly to environmental objectives, we may wonder whether promoting alternative currencies is the best alternative for achieving social objectives. If we assume, as I have done so far, that they will deliver on their social promises if their size increases, then we should also assume that they will also negatively impact people wider opportunities. I think other options, such as tax-funded social and cultural centres, or public libraries, may bring about similar social benefits, without the same unpalatable effects on opportunities. Though these are financed through taxation, they restrict people's formal freedom much less that a policy that would encourage the growth of alternative currencies. The same argument thus applies to both the environmental and social objectives.

In response, one could argue that, contrary to social and cultural centres, or to environmental taxation, alternative currency schemes need not be funded nor supported by public authorities. This is a misconception, though. Currently, alternative currencies do not require any support from the state (though, many do receive some support, see Attout et al. (2013)). However, if one takes seriously the argument that they need to grow, one must acknowledge that their use must no longer remain voluntary, but that it should be actively encouraged, if not imposed. The fact that their use is presently strictly voluntary is actually one reason why they have failed to achieve widespread adoption (Blanc, 2018). Therefore, increasing their use does require active support from the state, similarly to environmental taxation or public libraries.

Finally, what about their economic benefits? One may ask, first, whether it is justified to protect the local economy of a village, a town, or a region against foreign competition. Tackling pollution or social exclusion seems, at first sight, a valuable goal. But why would the economy of this particular village matter more than the economy of another? This raises complex concerns about economic protectionism that fall beyond 
the purpose of this article. Whether or not one shares these worries, we can have doubts that increasing the weight of alternative currencies would be the best strategy to protect the local economy. Taxation, quotas, or other protectionist policies may do the job more efficiently. I do not want to explore these possibilities any further, though, for I do not feel comfortable defending protectionism or protectionist policies. I just want to point out that, similarly to policies aimed at fostering social cohesion or environmental sustainability, protectionist policies should pass the following test: assuming that their objective is valuable, do they achieve it at the lowest cost for justice?

In this section, I argued that part of the answer concerns their effects on opportunities. On that regard, I showed that we can find policy options that are both empirically more promising and ethically less problematic than the policy that would consist in increasing the weight of alternative currencies in the economy. On the empirical side of the comparison, despite the fact that we lack adequate data to evaluate their effects, alternative currencies clearly appear as a weak candidate. On the normative side, and even if we assume equal effectiveness of different policies, the greater the weight of these currencies in the economy, the more they would reduce people's opportunities. I thus concluded that we should prefer policies that can achieve the same environmental, social or economic purposes while having a smaller negative impact on opportunities. The next section focuses on another important aspect of justice: the just distribution of the burdens of reducing environmental harm.

\section{Effects on the distribution of burdens}

My second objection concerns the distribution of the burdens of reducing environmental harm. It thus concentrates on the alleged environmental benefits of alternative currencies and leaves aside other objectives (to which I shall return in the next section). Reducing environmental harm is likely to be burdensome for individuals, as they will have to consume less of certain goods or at a higher price. How should these burdens be distributed? If one agrees that people should be held responsible for the cost that their choices entail for others, one relatively uncontroversial answer will be the "polluter pays" principle, or the idea that those who cause environmental harm (e.g. pollution) should pay for it.

In practice, the answer to this question is a little more complex, for justice and efficiency do not always go along with each other. A policy may lead to a just distribution of burdens, but be inefficient at reducing pollution. Conversely, a policy may efficiently tackle pollution, but fail to distribute burdens in a fair way. So which of these two should we choose? One way to avoid that problem is to leave the empirical part of the question aside. As I argued in section 3, the empirical literature is rather enthusiastic about environmental taxation (Fullerton et al., 2008). However, we do not have any data on large-scale experiments of alternative currencies. It may thus be difficult to compare how these two policies would reduce environmental harm. In this section, I will thus leave empirical matters aside and focus instead on the distributive consequences of these policies. In order to be able to make that normative comparison, I shall again assume that environmental taxation and the generalization of alternative currencies have the same ability to reduce environmental harm. That assumption may be 
controversial, but it will allow me to compare these policies in a way that is as charitable as possible to alternative currencies.

Note that each policy aims at reducing environmental harm through different means and thus involves a different distribution of burdens . Taxation increases the opportunity cost of consumption and/or production for those who cause harm. ${ }^{4}$ The generalization of alternative currencies in the economy, on the other hand, aims to reduce environmental harm by banning certain forms of trade altogether. Let's analyse each policy in turn.

If we take a look at these currencies in their present form, we will notice that they put the burden of reducing environmental harm on the benevolent, that is, on those willing to use these currencies, who are not necessarily the same as the polluters. As their use is purely voluntary, only those who wish to pay the cost of consuming local products while giving up on global ones will effectively pay it. That generous attitude might be praiseworthy but should not become a generalized rule for monetary policy. If implemented, the generalization of alternative currencies would entail that everybody will equally bear the costs of reducing pollution, for everybody will be barred from buying non-local products. It would have the same consequences for those who pollute as well as for those who do not, thus violating the "polluter pays principle". Therefore, generalizing the use of these currencies would imply that everyone has to pay for the harmful consequences of certain acts for which some do not have any responsibility. The greater their weight in the economy, the more they would impose the same restrictions on every economic agent, whatever one's consumer behaviour.

Environmental taxation, on the contrary, will make those who cause harm pay for it. Taxation maintains the formal freedom to do whatever one wants to do (including the consumption of polluting goods) while making the concrete possibility to consume or produce a commodity a function of its cost for others. In principle, the greater that cost, the greater the tax, and the lower the concrete possibility to consume or produce a given product. In sum, if we assume that both policies have the same likelihood to fulfil their environmental objective, taxing people for the harmful impact of their behaviour on the environment might yield a better combination of freedom and responsibility than the generalization of alternative currencies. It better respects people's formal freedom while making people pay for the cost that their consumption or production entails for others. Therefore, the universality of money and environmental sustainability are not necessarily incompatible. Again, they might be no need to abandon money's universality in order to achieve sustainability.

In response to my argument, one could argue that the burden of tax might fall disproportionately on the poor. For instance, a flat tax on motor fuels may hit the poor more than the rich because it reduces the disposable income of the former proportionally more than the latter. However, recent empirical research has shown that environmental taxation was not as regressive as it is often assumed to be (Fullerton et al., 2008; Sterner, 2012). Concerning fuel taxes, for instance, Sterner (2012) does not find any evidence of regressivity when lifetime income is used to measure the impact of the tax. Nevertheless, some economic agents with short-term foresight, or whose lack of resources prevents from planning for the long-term, may care primarily about the effects of the tax in the short run. In addition, taxation may also be regressive in other respects, namely gender or 
occupation. Part-time workers, who earn less but commute as much as full-time workers, may be disproportionately hit by the tax. Similarly, it may disadvantage rural workers as compared to town residents. These are perfectly legitimate worries. I argue, however, that, even if these taxes are regressive, the distributional consequences of environmental taxation could be addressed by income redistribution (Boyce, 2018). Environmental policies and distributive policies need not conflict with each other. Actually, a mix of environmental taxation and redistributive policies will respect freedom, responsibility and fairness much more than the generalization of alternative currencies. For the latter might make the poor much worse off than they are now, by strictly restricting their real opportunities. As we shall see in the next paragraphs, the possibility to compensate for such losses through income redistribution would be considerably reduced by such a generalization. Contrary to environmental taxation, its defenders cannot (or with great difficulties) appeal to income redistribution to compensate for its potential detrimental effects on the most disadvantaged members of society.

Before turning to the next section, it might be useful to make clear that, though these arguments suggest opposing the generalization of alternative currencies, they do not reject the possibility to support them altogether. To repeat, the point is that their growth would be both harmful and unnecessary, for other policies would achieve their aim in a more just way. But there is still a place for small-scale experiments, limited in scope and ambition, provided that they do not conflict with the demands of social justice.

\section{Effects on the possibility of redistributive policies}

Restricting the purchasing power of money according to geographic or communitarian criteria would harm justice for a third reason. Market societies generate substantial unjust inequalities of power and of opportunity (Piketty, 2013). Justice demands to reduce these inequalities, in part through taxation and redistribution of incomes and wealth. Among egalitarians, there is a recurrent debate on the right pattern of distribution. Some are in favour of radical distributive equality (e.g. Cohen, 2011) while others leave room for possible acceptable inequalities (e.g. Rawls, 1999). I shall not propose a new theory of distributive equality. I simply assume that the existence of unjust inequalities makes some redistribution necessary.

Generalizing the use of alternative currencies would greatly undermine the mere possibility to implement redistributive policies or make redistribution so complex that restricting money's purchasing power would lose any relevance. Redistributive policies rest on the capacity of the state to tax some people's incomes in order to redistribute them to other people. Taxation requires that all incomes are commensurable to each other: each person's income needs to be measured in a common unit so that all incomes are comparable, whatever the currency in which they are paid. Redistribution requires that currencies are convertible into each other: otherwise, incomes taxed in area A in the form of currency A could not be transferred to area B under another monetary form. Redistribution must take the form of money payments labelled in the currency effectively used by the receiver: unconvertible currencies are worthless outside of their town or community of origin. 
Recall that alternative currencies can have an effective impact on the economy or the environment only if they restrain economic activities locally, or within a given community. This implies that their convertibility must be limited, for otherwise one could easily avoid local restrictions by exchanging local money for universal money. Therefore, increasing their weight in the economy would seriously impede redistributive policies, by undermining the convertibility and commensurability of monetary incomes. To illustrate this point, consider an economy in which each town or region has its own currency only valid locally and in which, therefore, all exchanges take place locally. In this somehow extreme scenario, redistribution also takes place locally: each town's rich citizens pay taxes and each town's poor citizens receive transfers funded by those local taxes. Redistribution beyond the local level is impossible, for local currencies have no value outside a given geographic area.

One could argue that political borders between countries also restrict the scope of redistributive policies within a geographical area, and that this is often legitimate. First, note that the latter claim is controversial. Several "cosmopolitan" theorists have actually argued for global redistributive policies beyond borders (e.g. Van Parijs, 2007; Culp, 2014). Second, and most importantly, borders do not limit redistribution in the same way than the implementation on a large scale of alternative currencies would. It is in fact possible, and perhaps desirable, to transfer money to people in other countries. Currently, rich countries do not transfer as much wealth to poor regions as they possibly could. But it is up to these states' political bodies to decide whether to turn that possibility into policy. The large-scale implementation of alternative currencies, however, would impede the mere possibility of redistributing wealth within a wider political entity, whether or not it is deemed desirable to do so. For they must be non-convertible in other currencies in order to achieve their objectives. Therefore, whether the right scope of redistribution is national or whether it transcends national borders, that extreme scenario would hinder redistributive policies in both cases.

Another possible reply to my objections is that nobody has in mind anything close to that radical scenario. Universal currencies will always be dominant. Nowadays, after all, exchanges and incomes labelled in alternative currencies are taxed according to the law prevailing in the country where they take place. For instance, in Belgium, exchanges in local currencies are subject to a VAT tax and incomes received in such currencies to an income tax (Attout et al., 2013: 67-91). However, the law currently does not allow taxes to be paid in these currencies, so firms must carry out a sufficient part of their sales in euros. 5

The problem is that allowing people to exchange or pay taxes in universal currencies will weaken the ability of alternative currencies to effectively restrict exchanges locally or within a community. As I have argued above, the capacity of alternative currencies to effectively achieve sustainability or promote social cohesion depends on their ability to restrict exchanges locally. The more we allow for universal currencies to circulate alongside alternative currencies, the more we undermine the ability of alternative currencies to achieve their purpose, for people can escape restrictions by using euros or dollars.

In short, there is a trade-off between the possible achievements of alternative currencies and the requirements of just redistributive policies. The implementation of 
redistributive policies, on the one hand, calls for limiting the weight of alternative currencies in the economy. Their environmental, economic or social goals, on the other hand, appear to require a wider expansion of these currencies. What side of the dilemma should we choose? Actually, there is no need to sacrifice income distribution for environmental or social objectives. As I argued above, environmental taxation, for instance, can go along with income redistribution (Boyce, 2018). And tax-funded social and cultural centres, or public libraries, may bring about noticeable social benefits, without curtailing the redistribution of incomes and wealth. To the extent that we can implement policies that do not impede redistributive policies and that serve the same environmental or social purpose than alternative currencies, we must call for restricting the scope of alternative currencies in the economy.

In response, one could argue that alternative currencies need not be incompatible with income redistribution. One could achieve commensurability and convertibility through a complex system of multiple exchange rates (one for each currency compared to the central unit of value), which would need to take into account each currency's purchasing power. A central agency could be in charge of computing and publishing these exchange rates. There could also be an exchange market for alternative currencies, only available to state authorities. The state could then tax incomes labelled in numerous kinds of different currencies, compute their relative value, exchange them on the market, and then redistribute them throughout the country.

One can expect that this complex scheme will raise many practical difficulties and give rise to a huge bureaucratic machinery. It might also weaken the possibility to restrict a currency's purchasing power, as exchange markets will enable people to bypass such restrictions. In sum, it is hard to imagine how this scheme could be made compatible with justice in a way that is neither too complex nor a threat to its core objectives. Building a more environmentally friendly economy is certainly a desirable goal, but achieving such a goal through restricting the purchasing power of money is both undesirable and unnecessary compared to other alternative policies.

\section{Conclusion}

This paper argued that proponents of alternative currencies are stuck in a dilemma. Currently, these currencies are far from providing an effective response to the ecological, economic and social challenges that, according to their advocates, threaten our society and our economy. However, turning these currencies into effective channels of change might hurt justice, in a way that is perhaps not even necessary for achieving their objectives. Imposing stricter restrictions on money's purchasing power, even if it might lead to valuable environmental or social benefits, would generate three kinds of injustice. It would reduce people's real opportunities, produce an unjust distribution of the burdens of reducing environmental harm and hinder the possibility to redistribute incomes and wealth. Moreover, these restrictions are disproportionate to their aim. Their detrimental consequences on justice can hardly be justified by the pursuit of environmental or social objectives, for there exist other reforms, such as environmental taxation or publicly-funded social facilities, which may achieve similar objectives without curtailing the pursuit of social justice. 
There is, perhaps, one way out of that dilemma. Faced with the current inability of alternative currencies to fully fulfil their promises, and convinced that increasing the scale at which alternative currencies circulate may be an unreachable objective, several authors have argued that Local currencies, LETS, and Time Banks should be conceived as vectors of contestation. North (2007) describes them as part of a social movement that contests globalization, capitalism and impersonal market exchanges. Blanc (2018) acknowledges that these currencies have failed to affect the economy or the environment, but contends that it is often not their purpose (Blanc, 2018: 71-72). He argues that their main aim is to transform the nature of exchanges, to question the current state of money and to express one's discontent about the prevalence of market values. He supports the willingness of practitioners to build bottom-up alternatives to capitalism, whatever their impact, and even if the scope of such experiments is limited.

Leaving aside the question of whether contesting globalization, markets or capitalism is actually justified, one can still wonder whether, in practice, local currencies, LETS and other similar currencies can provide effective channels of contestation. Their ability to convey opposition to market values depends on their capacity to attract a sufficiently large number of members and to persuade them of the worth of contesting markets and capitalism. They need to appeal to people that are not already convinced by the necessity to reform the monetary system or to create an alternative to the market. These are real challenges. Williams et al. (2001) have shown that the British LETS mostly attracted poor workers or unemployed people that used them mainly as a survival strategy. Similarly, according to Gómez (2009), gaining additional revenues was the main motive of participation in Argentinian Trueques. Inclusion in a community can also constitute an important motive (Blanc, 2018: 61-62). However, even if some studies have shown that political contestation constituted part of the appeal of some French LETS (Servet et al., 1999), that motivation is not central to most alternative currency schemes (Blanc, 2018: 61-62).

This paper could not find any strong reason to encourage the development of alternative currencies, and argued forcefully against increasing their weight in the economy. However, there may be no reason to ban alternative currencies altogether. On the one hand, if the size of such experiments stays small, they will not have any serious impact on justice. On the other hand, liberal democracies guarantee the right of free association. This right includes the freedom to join and create small-scale local experiments, such as local currency schemes or LETS. I do not intend to ban gifts or informal exchanges. I do not want to blame employers who offer small in-kind benefits to their employees, or people who exchange gifts with their neighbours and relatives. Similarly, I admit that many employees, merchants and consumers may well freely agree to accept such currencies in payment or find value in their voluntary involvement in small-scale alternative currency schemes. Nevertheless, money's polyvalence matters for justice. It is crucial for the safeguard of everyone's access to opportunities, as well as for the design of just and efficient redistributive policies. Alternative currencies may seem charming and harmless in their present form. However, the hope to see them deliver significant benefits is unlikely to bear much fruit: either they stay small and renounce impacting the world in a significant way; or they grow and risk threatening social justice. 


\section{Acknowledgements}

The author wishes to thank John Eriksson, Clément Fontan, Marthe Nyssens, Camille Pascal, Katarina Pitasse Fragoso, Pierre-Etienne Vandamme, Andrew Williams and Danielle Zwarthoed, as well as two anonymous reviewers, for their insightful comments and suggestions on this article.

\section{Declaration of conflicting interests}

The author(s) declared no potential conflicts of interest with respect to the research, authorship, and/or publication of this article.

\section{Funding}

The author(s) received no financial support for the research, authorship, and/or publication of this article.

\section{Notes}

1. This also sets them apart from Bitcoin and other cryptocurrencies, which are valid across borders and for all kinds of goods and services. See Larue (2020a).

2. See for instance Rawls (2005: 187) as well as Sen (1992: xi).

3. On the distinction between formal freedom and real freedom, see Van Parijs (1995: 23-24) and Cohen (2011: 173-178).

4. Similarly, subsidies (for green energy, for instance) reward those whose actions benefit others. These can be seen as "negative taxation", for government subsidies are paid by collecting taxes.

5. Note that there are many possible tax exemptions, mostly in cases where these exchanges take place "informally" (Attout et al., 2013: 71). Finally, when currencies are not convertible, there is no standard defining how to value them, and therefore, no way to know how to tax exchanges labelled in such currencies (Attout et al., 2013: 75). It means that, in practice, many exchanges taking place within these schemes are exempt from taxation.

\section{References}

Aldridge TJ and Patterson A (2002) LETS Get real: Constraints on the development of local exchange trading schemes. Area 34(4): 370-381.

Arnsperger C (2011) Monetary federalism and the recovery of Swiss sovereignty: Enhancing Switzerland's financial autonomy through a cantonal system of complementary currencies. In: ECSA-Switzerland Conference "Aspekte der Souveränität in den Beziehungen der Schweiz zur Europäischen Union”, Vol. 11, Basel: Europainstitut.

Attout A, Clerc L, Cloot A, et al. (2013) Guide Pratique Des Monnaies Complémentaires. Bruxelles: Éditions du Réseau Financement Alternatif. Available at: https://www.financite.be/ sites/default/files/guide_pratique_des_monnaies_complementaires_0.pdf.

Blanc J (2018) Les Monnaies Alternatives. Paris: La Découverte.

Blanc J and Fare M (2013) Understanding the role of governments and administrations in the implementation of community and complementary currencies. Annals of Public and Cooperative Economics 84(1): 63-81. 
Blanc J and Fare M (2016) Turning values concrete: The role and ways of business selection in local currency schemes. Review of Social Economy 74(3): 298-319.

Bowring F (1998) LETS: An Eco-socialist initiative? New Left Review 232: 91-111.

Boyce JK (2018) Carbon pricing: Effectiveness and equity. Ecological Economics 150: 52-61.

Brooks S (2015) How green is Our money? Mapping the relationship between monetary systems and the environment. International Journal of Community Currency Research 19 D: 12-18.

Cohen GA (2011) On the Currency of Egalitarian Justice and Other Essays in Political Philosophy. Princeton: Princeton University Press.

Culp J (2014) Global Justice and Development. Basingstoke: Palgrave MacMillan.

Derudder P (2014) Les Monnaies Locales Complémentaires : Pourquoi, Comment? Paris: Yves Michel.

Dittmer K (2013) Local currencies for purposive degrowth? A quality check of some proposals for changing money-as-usual. Journal of Cleaner Production 54: 3-13.

Douthwaite R (2012) Degrowth and the supply of money in an energy-scarce world. Ecological Economics 84: The Economics of Degrowth: 187-193.

Dworkin R (1985) Liberalism. In: A Matter of Principle. Cambridge, Mass: Harvard University Press, pp.181-204.

Fare M and Ould Ahmed P (2017) Complementary currency systems and their ability to support economic and social changes. Development and Change 48(5): 847-872.

Fullerton D, Leicester A and Smith S (2008) Environmental Taxes. 14197, Working Paper, July. National Bureau of Economic Research. Available at: http://www.nber.org/papers/w14197 (accessed 25 February 2020).

Gómez GM (2009) Argentina's Parallel Currency: The Economy of the Poor. Series on Financial History 11. London: Pickering \& Chatto Publishers.

Graugaard JD (2012) A tool for building community resilience? A case study of the lewes pound. Local Environment 17(2): 243-260.

Gregory L (2009) Spending time locally: The benefit of time banks for local economies. Local Economy: The Journal of the Local Economy Policy Unit 24(4): 323-333.

Hammar H, Löfgren $\AA$ and Sterner T (2004) Political economy obstacles to fuel taxation. The Energy Journal 25(3): 1-17.

Larue L (2020a) A conceptual framework for classifying currencies. International Journal of Community Currency Research 24(1): 45-60.

Larue L (2020b).The ecology of money: A critical assessment. Ecological Economics 178, Article 106823.

Larue L, Meyer C, Hudon M, et al. (2022) The Ethics of Alternative Currencies. Business Ethics Quarterly: forthcoming.

Lietaer BA, Arnsperger C, Goerner S, et al. (2012) Money and Sustainability: The Missing Link. Axminster: Triarchy Press.

Marshall AP and O'Neill DW (2018) The Bristol pound: A tool for localisation? Ecological Economics 146(Supplement C): 273-281.

Meyer C and Hudon M (2017) Alternative organizations in finance: Commoning in complementary currencies. Organization 24(5): 629-647.

Meyer C and Hudon M (2018) Money and the commons: An investigation of complementary currencies and their ethical implications. Journal of Business Ethics 160: 277-292. 
Michel A and Hudon M (2015) Community currencies and sustainable development: A systematic review. Ecological Economics 116: 160-171.

Mildenberger CD (2019) Against Monetary Utopias. In: Money Workshop, Groningen, 2019.

Nakazato H and Hiramoto T (2012) An empirical study of the social effects of community currencies. International Journal of Community Currency Research 16(D): 124-135.

North P (2007) Money and Liberation: The Micropolitics of Alternative Currency Movements. Minneapolis: University of Minnesota Press.

Oliver Sanz E (2016) Community currency (CCs) in Spain: An empirical study of their social effects. Ecological Economics 121(Supplement C): 20-27.

Ould Ahmed P (2015) What does 'solidarity economy' mean? Contours and feasibility of a theoretical and political project. Business Ethics: A European Review 24(4): 425-435.

Peacock MS (2000) Local exchange trading systems: A solution to the employment dilemma? Annals of Public and Cooperative Economics 71(1): 55-78.

Piketty T (2013) Le Capital Au XXIe Siècle. Les livres du nouveau monde. Paris: Seuil.

Place $\mathrm{C}$ and Bindewald L (2015) Validating and improving the impact of complementary currency systems through impact assessment frameworks. International Journal of Community Currency Research 19: 152-164.

Rawls J (1999) A Theory of Justice, Revised edition Cambridge, Mass.: Belknap Press.

Rawls J (2005) Political Liberalism, Expanded Edition Columbia Classics in Philosophy 4. New York, N.Y.: Columbia university press.

Sen AK (1992) Inequality Reexamined. New York: Russell Sage Foundation.

Servet J-M, Bayon D, Blanc J, et al. (1999) Une Économie Sans Argent: Les Systèmes D'Echange Local. (ed. J-M Servet). Paris: Éditions du Seuil.

Seyfang G and Longhurst N (2013) Growing green money? Mapping community currencies for sustainable development. Ecological Economics 86. Sustainable Urbanisation: A resilient future: $65-77$.

Sterner T (2007) Fuel taxes: An important instrument for climate policy. Energy Policy 35(6): 3194-3202.

Sterner T (2012) Distributional effects of taxing transport fuel. Energy Policy 41. Modeling Transport (Energy) Demand and Policies: 75-83.

Stodder J (2009) Complementary credit networks and macroeconomic stability: Switzerland's wirtschaftsring. Journal of Economic Behavior \& Organization 72(1): 79-95.

Van Parijs P (1995) Real Freedom for All. Oxford Political Theory. Oxford: Oxford University Press.

Van Parijs P (2007) International distributive justice. In: Goodin RE, Pettit P and Pogge T (eds) $A$ Companion to Contemporary Political Philosophy. Oxford: Blackwell, pp.638-652.

Williams CC (1996) Local exchange and trading systems: A new source of work and credit for the poor and unemployed? Environment and Planning A: Economy and Space 28(8): 1395-1415.

Williams CC, Aldridge TJ, Lee R, et al. (2001) Bridges into work? An evaluation of local exchange and trading schemes (LETS). Policy Studies 22(2): 119-132.

\section{Author biography}

Louis Larue is a researcher in practical philosophy at the University of Gothenburg, Sweden. His research focuses on issues of justice in finance and money, and on several topics in the philosophy of economics. 